\title{
Planejamento da Alternância na formação de professores de Ciências na Educação do Campo
}

\author{
Elisandra Carneiro de Freitas Cardoso \\ Universidade Federal de Goiás - UFG, Brasil \\ Marilda Shuvartz \\ Universidade Federal de Goiás - UFG, Brasil
}

\begin{abstract}
RESUMO
O presente trabalho objetiva compreender o papel do planejamento pedagógico na formação de professores de ciências no curso de Licenciatura em Educação do Campo da UFG/Regional Goiás. Fundamentamos as reflexões no campo teórico da Educação do Campo e da formação de professores de Ciências, por meio de abordagem qualitativa e de procedimentos metodológicos da pesquisa participante, realizando a coleta de dados através da participação em reuniões de colegiado e planejamento do curso. A análise nos permitiu inferir que o planejamento é um elemento da prática pedagógica dos professores formadores e que o compromisso com o trabalho coletivo se apresenta de duas formas distintas: ora o trabalho coletivo aparece como elemento facilitador da Alternância, ora a ausência dos formadores restringe o comprometimento com uma formação integrada entre os tempos e os espaços educativos. Fator esse que não coaduna com o movimento de Educação do Campo pautado na coletividade e na formação integral do campesinato.
\end{abstract}

PALAVRAS-CHAVE: Educação do Campo. Formação de professores de ciências. Planejamento da Alternância.

\section{ALTERNATION PLANNING IN THE TRAINING OF SCIENCE TEACHERS IN RURAL EDUCATION}

\begin{abstract}
The present work aims to understand the role of pedagogical planning in training of Science teachers at graduation in Rural Education at UFG/Regional Goiás. We based our reflections in theoretical field of Rural Education and the training of science teachers, through qualitative approach and methodological procedures of participatory research, carrying out data collection through participation in collegiate meetings and course planning. The analysis allows us to infer that planning is an element of the pedagogical practice of teacher educators and that the commitment to collective work is presented in two different ways: sometimes collective work appears as a facilitating element for Alternation, sometimes the absence of trainers restricts the commitment to an integrated training between times and educational spaces. This factor does not agree with the Rural Education movement based on the community and the integral formation of the peasantry.
\end{abstract}

KEY WORDS: Rural education; Science teachers' formation; Alternation planning. 


\section{LA BASE CURRICULAR COMÚN NACIONAL Y LA LEY $\mathbf{N}^{\circ}$ 13.415/2017: UNA SUPUESTA DECURRICULARIZACIÓN}

\section{RESUMEN}

El presente trabajo tiene como objetivo comprender el papel de la planificación pedagógica en la formación de profesores de ciencias en la carrera de Grado en Educación del Campo de la UFG / Regional Goiás. Nosotros basamos las reflexiones en el campo teórico de la Educación del Campo y en la formación de profesores de ciencias, con un enfoque cualitativo y procedimientos metodológicos de investigación participante, llevando a cabo la recolección de datos a través de la participación en reuniones colegiadas y planificación del curso. El análisis permitió inferir que la planificación es un elemento de la práctica pedagógica de los formadores de docentes y que el compromiso con el trabajo colectivo se presenta de dos formas distintas: a veces el trabajo colectivo aparece como un elemento facilitador de la Alternancia, a veces la ausencia de formadores restringe la apuesta por una formación integrada entre tiempos y espacios educativos. Este factor no está de acuerdo con el movimiento de Educación del Campo basado en la colectividad y en la formación integral del campesinado.

PALABRAS CLAVE: Educación del Campo. Formación de profesores de ciencias. Planificación de Alternancia.

\section{INTRODUÇÃO' 1}

Este trabalho constitui-se um recorte da tese de doutorado intitulada "A formação de professores de ciências: tecendo tramas na Alternância", defendida no Programa de Pósgraduação em Educação em Ciências e Matemática da Universidade Federal de Goiás no ano de 2020.

Desde sua origem, um dos elementos identitários da Educação do Campo é a valorização do educador como uma das frentes de luta e de resistência pelos direitos dos povos do campo. Segundo Caldart (2011), o movimento construiu um conceito abrangente de educador, pois identificou que este tem como trabalho principal o fazer e o pensar a formação humana. Neste caminho, o projeto de Educação do Campo insiste na necessidade de políticas e projetos de formação de educadoras e educadores do campo.

Como resultado de um conjunto de políticas públicas, emergentes das lutas e demandas dos movimentos sociais e das relações de forças estabelecidas no campo político, a Licenciatura em Educação do Campo é uma nova modalidade de graduação nas universidades públicas brasileiras, cujos principais destinatários são os próprios sujeitos camponeses, quer sejam eles professores que atuam em escolas do campo, quer sejam jovens camponeses que almejam se tornar educadores. Portanto, esta Licenciatura tem como objetivo formar e habilitar

\footnotetext{
${ }^{1}$ Este trabalho está vinculado à Rede de Pesquisadores sobre professores no Centro-Oeste (Redecentro).
} 
profissionais do próprio campo para atuação nos anos finais do Ensino Fundamental e Médio, assim como na gestão de processos educativos escolares e comunitários. Esses cursos devem promover uma estratégia metodológica de formação de educadores que tenha como pilar central a formação para docência multidisciplinar por áreas de conhecimento (MOLINA; ANTUNESROCHA, 2014).

O curso de Licenciatura em Educação do Campo da UFG (LEdoC/UFG), Regional Goiás, foi criado a partir da concorrência no Edital de Seleção de 31 de agosto de 2012, e aprovados pela Portaria N. ${ }^{\circ}$ 72, de 21 de dezembro de 2012, N. ${ }^{\circ}$ 02/2012 - SESU/SETEC/ SECADI/MEC da Secretaria de Educação Continuada, Alfabetização, Diversidade e Inclusão (SECADI), publicada no Diário Oficial da União de 27 de dezembro de 2012 e autorizados pela Resolução Consuni n. ${ }^{\circ}$ 21/2013, de 17 de maio de 2013.

A LEdoC/UFG-Regional Goiás é um curso presencial, preferencialmente noturno, que funciona no regime de Alternância e oferta a formação na área de Ciências da Natureza. O curso oferece 40 vagas anuais, com o ingresso a partir de um processo seletivo via vestibular específico, realizado pelo Centro de Seleção da UFG.

Ademais, o curso ocorre em regime de Alternância entre o Tempo Universidade (TU) e o Tempo Comunidade (TC), de modo que o TU corresponde ao período em que os graduandos estão na universidade frequentando a maioria dos componentes curriculares do curso, enquanto no TC os discentes retornam para suas comunidades, mantendo o vínculo com as mesmas e sendo orientados em seus estudos de formação.

A Alternância constitui-se por uma matriz teórica e metodológica em construção que inicia a sua história, no Brasil, na Educação básica e profissional, e se constrói no âmbito do Movimento da Educação do Campo. Estabelece uma forma de organização do processo educativo que conjuga diferentes saberes distribuídos em espaços e tempos formativos. Nestes, os sujeitos desenvolvem sua formação dentro dos paradigmas de valorização da identidade, da cultura, da territorialidade e da articulação entre educação formal e os saberes da vida (BRASIL, 2020).

A origem dessa proposta pedagógica resulta do desencanto com a educação formal oferecida aos filhos de camponeses franceses. Devido ao fato de atender a dificuldade de conciliar os estudos com a permanência no campo é que a Pedagogia da Alternância tem como eixo central a organização do processo educativo, tanto na vivência na instituição escolar como no meio familiar, comunitário e do trabalho no campo.

Assim, a partir de uma perspectiva de compreensão e transformação da realidade com o sujeito que nela vive, o movimento de Educação do Campo tem multiplicado experiências de formação por Alternância como eixo central de formação campesina (SILVA, 2015). Nesse sentido, no âmbito das políticas públicas, a Alternância consolida-se como proposta pedagógica 
da Educação do Campo no Brasil, corroborada pelos documentos oficiais como o Parecer CNE/CEB 36/2001, que institui Diretrizes Operacionais para a Educação Básica nas Escolas do Campo e o Parecer CEB/CNE/MEC n. 1/2006 que regulariza o calendário de Alternância na Educação Básica.

Especialmente sobre a formação de professores, o Decreto n. 7352 de 2010, que dispõe sobre a política de Educação do Campo e o Programa Nacional de Educação na Reforma Agrária - Pronera, em seu artigo $5^{\circ}$ manifesta:

\begin{abstract}
$\S 20$ A formação de professores poderá ser feita concomitantemente à atuação profissional, de acordo com metodologias adequadas, inclusive a pedagogia da alternância, e sem prejuízo de outras que atendam às especificidades da educação do campo, e por meio de atividades de ensino, pesquisa e extensão. $\S 30$ As instituições públicas de ensino superior deverão incorporar nos projetos político-pedagógicos de seus cursos de licenciatura os processos de interação entre o campo e a cidade e a organização dos espaços e tempos da formação, em consonância com as diretrizes estabelecidas pelo Conselho Nacional de Educação.
\end{abstract}

Desta forma, as atividades formativas nos cursos de Licenciatura em Educação do Campo trazem novas lógicas de organização do trabalho pedagógico no Ensino Superior. Na formação docente, a Alternância contribui com a presença de princípios como: o fortalecimento do diálogo de saberes; o protagonismo dos educandos nos processos formativos; a relação com a Educação Popular em uma perspectiva de educação emancipatória; o papel da pesquisa como princípio educativo; o estudo da realidade e a transformação desta a partir da práxis (CARDOSO, 2020).

Nessa perspectiva, o trabalho pedagógico dos professores formadores nas Licenciaturas em Educação do Campo não se limita apenas ao tempo de sala de aula, mas relaciona-se a um compromisso com diversas dimensões humanas na formação dos educandos. Nestes cursos são papéis fundamentais dos professores formadores

[...] a participação nos planejamentos coletivos da área de conhecimento em que atua, como também da subárea de atuação; a participação nas atividades de TC, que incluem planejar, acompanhar e avaliar atividades de TC dos discentes, que é uma ação fundamental e condição necessária ao alcance dos objetivos a que o curso se propõe (MOLINA; ROCHA; SANTOS, 2019, p. 314).

Como vemos, o trabalho docente nestas licenciaturas incorpora especificidades da organização pedagógica da Alternância e da formação por área do conhecimento que dialoguem com uma formação humana dos educadores e educadoras campesinas. Desta forma, os diferentes cursos no país organizam-se pedagogicamente no regime da Alternância, escolhendo em cada realidade e projeto distintos a forma mais adequada para consolidar essa proposta. Para 
Molina (2012), a institucionalização e consolidação da Alternância como modalidade de oferta da Educação Superior, na perspectiva da garantia do direito à educação para os sujeitos do campo, considerando as especificidades de seu modo de produzir a vida, se constituem como importante território conquistado pela Educação do Campo.

É neste contexto que o presente trabalho objetiva compreender o papel do planejamento pedagógico da alternância na formação de professores de ciências no curso de Licenciatura em Educação do Campo da UFG/Regional Goiás. Para isso, fundamentamos nossas reflexões no campo teórico da Educação do Campo e da formação de professores de ciências e do campo.

\section{METODOLOGIA}

Este estudo tem caráter qualitativo, pois é rico em valores e sentidos que só podem ser compreendidos por meio de uma disposição maior do pesquisador em perceber e expor os seus significados (MINAYO, 1994). Entendemos que a abordagem qualitativa é a que melhor contempla esta investigação, tendo em vista que pode proporcionar uma compreensão detalhada do problema de pesquisa escolhido.

Sob esta abordagem, optamos por realizar a pesquisa de forma a construir um saber compartilhado com os sujeitos envolvidos. Então, utilizamos a pesquisa participante como metodologia de investigação, já que esta apoia-se em um comprometimento pessoal entre o pesquisador e o objeto de pesquisa, ultrapassando, assim, os limites do conhecer e do explicar e busca o compreender para servir (BRANDÃO, 1999).

Com tais procedimentos metodológicos de investigação, aproximamo-nos da realidade social da formação de professores de ciências na Educação do Campo, por meio do encontro com os sujeitos que estão imersos nessa situação social. Entendemos que a partir de uma proposta de investigação que leve em consideração a práxis é que se torna possível o pensar verdadeiro e crítico sobre o objeto de estudo, anunciando a realidade e possibilitando a sua transformação.

Para a coleta de dados desta pesquisa, participamos de reuniões de planejamento e colegiados de curso, com vistas à inserção do pesquisador na realidade a ser investigada. Acreditamos que os momentos de discussão e planejamento coletivos proporcionam condições de compreender melhor os pensamentos e as intencionalidades dos sujeitos envolvidos na formação de professores de ciências da LEdoC.

Nesse caminho, delimitamos o ano letivo de 2018 para acompanhamento das atividades do curso, quando coletamos os dados nas reuniões de colegiado do curso, nas reuniões de planejamento do TC e no desenvolvimento das atividades durante o TC, no período dos 
semestres de 2018-1 e 2018-2. Assim, foram acompanhadas oito reuniões de colegiado e cinco reuniões de planejamento e avaliação do TC, totalizando treze reuniões que foram gravadas e transcritas para serem utilizadas na análise.

Para o tratamento dos dados obtidos, recorremos à técnica da análise de conteúdo proposta por Bardin (2010, p. 44), que se constitui em:

Um conjunto de técnicas de análise das comunicações visando obter por procedimentos sistemáticos e objetivos de descrição do conteúdo das mensagens indicadores (quantitativos ou não) que permitam a inferência de conhecimentos relativos às condições de produção/recepção (variáveis inferidas) destas mensagens. [...] Esta abordagem tem por finalidade efetuar deduções lógicas e justificadas, referentes à origem das mensagens tomadas e consideração.

Desta forma, utilizando a análise de conteúdo, procedemos à fase de análise dos dados obtidos das reuniões, procurando inferir conhecimentos relativos ao planejamento da alternância na formação de professores do campo por área do conhecimento dentro da proposta de Alternância.

\section{RESULTADOS E DISCUSSÃO}

O planejamento é um processo de racionalização, organização e coordenação da atividade docente que articula o processo educativo com o contexto social. A instituição educativa, assim como seus sujeitos (professores, alunos, comunidade) são integrantes de relações sociais e o que acontece no meio escolar está permeado por influências econômicas, políticas e culturais que caracterizam a sociedade de classes. Nesse contexto, a ação de planejar é uma atividade consciente de previsão das ações docentes fundamentadas em opções políticopedagógicas, tendo como referência a realidade educativa concreta (LIBÂNEO, 1994).

Considerando a importância do planejamento, a UFG normatiza essa atividade docente no Regimento Geral dos Cursos de Graduação da UFG e prevê a sua efetivação no calendário acadêmico:

Art. 100. Cada disciplina ou eixo temático/módulo terá o seu plano de ensino elaborado pelo respectivo professor ou grupo de professores e aprovado pelo conselho diretor da unidade responsável pela disciplina ou pelo eixo temático/módulo nos termos do Regimento da UFG (UFG, 2012, p. 30).

Portanto, a atividade de planejamento dos processos formativos faz parte da função docente e se torna condição indispensável ao trabalho do formador no curso de Licenciatura em Educação do Campo na UFG. Deste modo, vários foram os momentos em que o planejamento 
de atividades foi pauta das reuniões acompanhadas.

No início do semestre letivo, as reuniões de colegiado tinham o caráter de organização e eram carregadas de momentos de distribuição das disciplinas, organização do calendário do curso $^{2}$, aprovação dos planos de disciplina do semestre, entre outras demandas de forma burocrática.

Esse calendário que eu enviei pra todos é o calendário de todo ano letivo de 2018. Então aqui nós vamos definir e pensar muito bem as datas destinadas ao Tempo Comunidade no primeiro e no segundo semestre. $\left(\mathrm{C}^{3}\right.$; grifo nosso).

No sentido proposto pela fala acima, o planejamento aparece como um elemento organizador do processo formativo. Nas primeiras reuniões de colegiado, ele surge como parte do trabalho docente para estabelecer a distribuição de disciplinas e do calendário específico do curso.

No decorrer do diálogo entre os participantes fica clara a postura da coordenação de curso em oferecer uma proposta de distribuição das disciplinas e de calendário, portanto, de planejamento. Ao apresentar aos pares, a proposta é discutida entre eles, o que demonstra uma sensibilidade quanto à participação do coletivo nas decisões sobre o desempenho do curso. No entanto, a proposta vem pronta da coordenação e é posta em votação, portanto, não se configura exatamente como uma construção coletiva, visto que não existe o processo de escuta e diálogo entre todos os sujeitos na organização inicial da proposta.

Além disso, outro elemento presente na prática pedagógica dos professores formadores na universidade é a aprovação dos planos de ensino de cada disciplina no início do semestre. Durante o período da pesquisa, não houve momentos coletivos de debate sobre o desenvolvimento de cada disciplina, apenas a leitura e breves relatos dos planos de ensino. Relativo a isso, entendemos que os momentos de discussão sobre o processo formativo dos estudantes, via planejamento coletivo, deveriam ser ricos de reflexão crítica, diálogos e formação mútua. Todavia, o momento que presenciamos evidenciou apenas a realização de um ritual de leitura dos planos de ensino ou relatos breves do planejamento disciplinar por cada formador, cumprindo uma função meramente administrativa e burocrática, tornando-se espaço estéril, vazio, estático e fastidioso, portanto, distante de um trabalho coletivo.

\footnotetext{
${ }^{2}$ A Licenciatura em Educação do Campo/UFG-Regional Goiás possui calendário específico do curso em que organiza os períodos de Tempo Comunidade e Tempo Universidade atendendo às disposições do calendário institucional da UFG.

${ }^{3}$ A fim de não possibilitar a identificação dos participantes da pesquisa, substituímos neste texto os nomes destes sujeitos por um código desidentificador composto por uma letra e um número, quando houver mais de um sujeito na mesma categoria. Os professores formadores do curso são identificados pela letra "P", o coordenador de curso pela letra "C", o coordenador de Estágio pelas letras "CE", os discentes pela letra " $D$ " e a pesquisadora responsável pela "I". Nos casos dos discentes e docentes, em que existe mais de um sujeito identificado com a mesma letra, estas serão seguidas também de números, de acordo com a ordem que aparecem nas transcrições; exemplo: "D01”.
} 
Ademais, ressaltamos que, um curso que tem o compromisso, firmado no PPC, com uma formação interdisciplinar carrega também a necessidade de uma postura dialógica de criação e de recriação das práticas pedagógicas compromissadas com a restauração da humanidade. Logo, tal postura demanda tempo, presença, participação e engajamento.

Diante disto, assumimos que é possível pensar em estratégias de planejamento e diálogo que, mesmo dentro de uma estrutura de matriz curricular ainda compartimentada, possam possibilitar momentos de reflexão e de trabalho coletivo dos formadores com vistas à proposição de estratégias metodológicas que alcancem o diálogo das diferentes áreas do conhecimento no processo educativo, objetivando uma formação mais próxima da interdisciplinaridade. Nesse sentido, concluímos que o formato de apresentação dos planos de disciplina proporcionado nas atividades coletivas se torna obstáculo para um trabalho pedagógico comprometido com uma organização coletiva.

Em contrapartida a Alternância (Tempo Universidade [TU]+ Tempo Comunidade [TC]) foi assumida pelo curso nas atividades de planejamento. As discussões destes momentos envolviam: 1) Organização da disciplina de Experiência Compartilhada ${ }^{4}$ : definição dos formadores e dos grupos; 2) Organização de atividades coletivas do TC: abertura e encerramento; 3) Cronograma de atividades; 4) Condições de infraestrutura durante o TC, principalmente relacionadas ao transporte; 5) Escolha do tema gerador; 6) Instrumentos pedagógicos (Caderno de Realidade, Plano de Estudos e Seminário de Socialização); 7) Avaliação das atividades realizadas; 8) Demandas das comunidades; 9) Compreensão dos sujeitos sobre a Alternância e como ela se organiza no curso; 10) Envolvimento dos sujeitos na Alternância do curso.

Passamos a apontar três importantes momentos de planejamento da Alternância:

1) Organização da disciplina de Experiência Compartilhada: definição dos formadores e dos grupos

Um momento importante do planejamento da Alternância no curso se dá na organização dos grupos do TC. Na disciplina "Experiência Compartilhada", os alunos são divididos em grupo de acordo com a sua região de origem e afinidade. Cada grupo fica sob a orientação de um professor formador responsável por desenvolver as atividades do TC na disciplina. Do ponto de vista organizacional e administrativo do curso, as disciplinas "Experiência Compartilhada"

\footnotetext{
${ }^{4}$ No curso o TC é organizado dentro das "Atividades Integradoras" que são compostas pelas disciplinas "Experiência Compartilhada" (I a IV) e "Orientação de Trabalho de Conclusão de Curso" (I e II). As disciplinas "Experiência Compartilhada" são desenvolvidas do $1^{\circ}$ ao $4^{\circ}$ período do curso, com carga horária de $64 \mathrm{~h}$ cada. As atividades a serem desenvolvidas durante o TC são planejadas e orientadas com antecedência no TU e são realizadas no âmbito das disciplinas "Experiência Compartilhada" até o $4^{\circ}$ período do curso. Do $5^{\circ}$ ao $8^{\circ}$ período o TC é desenvolvido nas disciplinas "Estágio Supervisionado" (I a IV) e "Orientação de Trabalho de Conclusão de Curso" (I e II).
} 
(I a IV) são desenvolvidas no formato de subturmas, sendo registradas no Sistema Integrado de Gestão de Atividades Acadêmicas (SIGAA), cada subturma com seu respectivo docente e discentes. Esta organização é realizada a partir do diálogo com os alunos para o levantamento das comunidades de origem, de onde decorrem os grupos de trabalho dos alunos para o primeiro semestre de 2018.

O quadro a seguir apresenta o resultado da organização das subturmas de "Experiência Compartilhada" no ano de 2018, com base na triangulação dos dados do diário de campo da pesquisadora, nas transcrições das reuniões e dos Diários de Turma.

Quadro 1: Organização das disciplinas “experiência compartilhada” no ano de 2018.

\begin{tabular}{|c|c|c|c|}
\hline DISCIPLINA & PROFESSOR & ALUNOS $^{5}$ & CARACTERIZAÇÃO DA COMUNIDADE \\
\hline $\begin{array}{c}\text { Experiência } \\
\text { Compartilhada I } \\
\text { e II }\end{array}$ & P03 & 06 & $\begin{array}{c}\text { - Município: Aruanã; } \\
\text { - Localidade: Aldeia BdéBure, terra Indígena } \\
\text { Karajá III; }\end{array}$ \\
\cline { 2 - 4 } & $\mathrm{P} 12$ & 07 & $\begin{array}{c}\text { - Município: Goiás; } \\
\text { - Localidade: área urbana do município de } \\
\text { Goiás; }\end{array}$ \\
\hline $\begin{array}{c}\text { Experiência } \\
\text { Compartilhada } \\
\text { III e IV }\end{array}$ & P04 & 04 & $\begin{array}{c}\text { - Município: Goiás; } \\
\text { - Localidade: Comunidade Quilombola } \\
\text { localizada no Bairro Alto Santana, na área } \\
\text { urbana do município de Goiás; }\end{array}$ \\
\cline { 2 - 4 } & & 04 & $\begin{array}{c}\text { - Localidade: Assentamento Mosquito } \\
\text { - Município: Goiás }\end{array}$ \\
\hline
\end{tabular}

Fonte: Cardoso (2020).

Sobre a caracterização da comunidade e composição dos grupos da disciplina "Experiência Compartilhada" (I a IV), verificamos que os grupos são compostos de forma plural. Percebemos que a maior parte dos grupos (três, dos cinco) são compostos por discentes de área urbana, dado que dialoga com Castro (2020) sobre o perfil discente do LEdoC/UFG Regional Goiás. De acordo com a autora, $82 \%$ dos estudantes do curso, no ano de 2020, são habitantes de territórios urbanos, sejam eles do centro de cidades ou de periferia; e $14 \%$ dos estudantes são habitantes de territórios campesinos (assentamentos e comunidade tradicionais do campo). Desta forma, a composição dos grupos baseada no território de habitação dos discentes demonstra que a maior parte dos discentes não tem vínculo direto com a vida no

\footnotetext{
${ }^{5}$ Entre o semestre de 2018-01 e o semestre de 2018-02 houve variação em relação à quantidade de alunos por grupo devido a desistências. No entanto, optamos por não trazer este dado, por considerar não relevante para este trabalho.
} 
campo. Por um lado, isso justifica que algumas ações do TC são organizadas na cidade e no espaço da universidade, diferente do que se compreende o TC previsto no projeto Pedagógico do curso. Assim, entendemos que tal fato tem se distanciado dos objetivos da Licenciatura em Educação do Campo, que é justamente valorizar o vínculo e a identidade camponesa.

Outra discussão presenciada no planejamento da Alternância foi a definição das atividades a serem desenvolvidas no TC. Constatamos que houve reuniões periódicas na universidade entre o professor formador e os discentes de cada subturma para planejar, refletir, avaliar e propor novas ações durante este tempo formativo, o que coaduna com o que propõe Molina, Rocha e Santos (2019) sobre as atividades docentes para o Tempo Comunidade nas Licenciaturas em Educação do Campo. Nos dois semestres em que esta pesquisa acompanhou o desenvolvimento da Alternância, a maior parte dos discentes eram residentes no município de Goiás, o que justificava as reuniões no espaço da universidade. A exceção estava na subturma que desenvolveu as atividades em Aruanã, e que tiveram todas as atividades realizadas na comunidade.

\section{2) Escolha do tema gerador}

A Educação Popular compõe uma matriz formativa da Educação do Campo. E nesta os temas geradores ocupam lugar de destaque na organização pedagógica das propostas educativas. Segundo Silva (2007, p. 13), a Educação Popular via tema gerador procura:

[...] romper a dissociação entre conhecimento científico e cidadania, observada na tradição sociocultural dominante, do colonizador, considerando conhecimento, tanto a realidade local - reflexo de um contexto sócio-histórico, concretamente construído por sujeitos reais -, quanto o processo de produção da cultura acadêmica, proposto a partir do diálogo entre saberes, popular e científico, em que a apreensão do conhecimento é construída coletivamente, a partir da análise das contradições vivenciadas na realidade local.

Isso posto, fica esclarecida a justificativa da adoção de temas geradores na formação de professores de ciências no campo. Assim, identificamos que, já nas primeiras reuniões de planejamento, as falas do coordenador sinalizaram a adoção de temas geradores na Alternância do curso em semestres anteriores. A partir do trabalho já desenvolvido, no semestre de 201801, a comunidade do Assentamento Mosquito, demanda a discussão sobre a preservação das nascentes.

Trabalhamos 2017 com a discussão das temáticas soberania alimentar e a agricultura familiar e o agronegócio. Acho que a gente precisa dar continuidade a essa temática. A esse respeito, já tivemos discussões iniciais com o tema: Produção de água nas comunidades rurais. Por que eu pensei 
nesse tema!? Primeiro que é uma demanda que a D02 levantou, a proteção de nascentes. (C).

Verificamos que a proposta da temática sobre "produção de água nas comunidades rurais" surge, portanto, do trabalho desenvolvido no TC do semestre anterior. Consideramos que este fato ratifica o compromisso com a continuidade do trabalho desenvolvido e a articulação entre os Tempos Comunidades de semestres distintos. Assim, é fato que a escolha de temáticas se enquadra nos temas geradores da Educação Popular e do Ensino de Ciências, pois observamos que, embora outros professores ou discentes não tenham se manifestado em relação a outras propostas de temas, comprometendo um processo democrático de seleção, o tema escolhido surge como demanda de uma das comunidades acompanhadas pelo curso.

No semestre de 2018-2, a escolha do tema gerador se deu de forma distinta. Apesar de um primeiro levantamento da temática em reunião de planejamento com a participação dos professores formadores, foi levantada a seguinte consideração:

Acho que tá faltando algo fundamental aqui que é a participação dos nossos alunos em relação ao tema. [...] porque vai ser algo que eles percebem da própria comunidade que eles fazem parte. É preciso essa figura desses alunos aqui nesse momento de discussão. (C; grifo nosso).

Diferente do semestre anterior, em que o tema surge da demanda de uma comunidade, no semestre de 2018-2 é construído um processo mais democrático de escuta dos discentes do curso. Assim, em reunião específica entre a Coordenação de TC e os discentes, após reflexões e discussões definiram o tema gerador "Preservação ambiental" para o semestre de 2018-2.

Neste contexto, compreendemos que a forma de escolha do que denominamos "tema gerador" se propõe a analisar a realidade de forma contextualizada e interdisciplinar. A investigação temática, conforme propõe Paulo Freire (2019) envolve investigar o próprio pensar do povo em um processo de busca, de conhecimento e de trabalho em equipe interdisciplinar. De modo que, a partir do universo temático recolhido na investigação, o mesmo será devolvido aos sujeitos como problema ou temática de estudo.

Assim, compreendemos que, o que o autor propõe para o desenvolvimento do processo formativo a partir da escolha do tema gerador é que haja a elaboração de uma rede temática, seguida de um estudo sistemático e interdisciplinar de cada área do saber para redução dos temas (descodificação) a serem desenvolvidos, e, por fim, o planejamento do programa, das aulas, das atividades com a elaboração de material didático (codificação).

Todavia, no desenvolvimento das atividades de planejamento do curso, percebemos que a escolha do tema gerador não adota fielmente a elaboração da investigação temática freiriana. A escolha do tema gerador parte do contexto das comunidades via interpretação dos discentes 
do curso. Além disso, foi possível perceber que à medida que o trabalho coletivo faz parte do planejamento pedagógico do curso, este torna-se elemento fundamental para a adoção de uma proposta de tema gerador mais próxima da Educação Popular e, assim, efetivamente mais comprometida com uma educação dialógica, emancipatória e, portanto, humanizadora.

Sobre este aspecto, Bittencourt e Molina (2019), quando descrevem a utilização do tema gerador na formação de professores do campo, confirmam que mais importante do que a metodologia a ser empregada é a concepção de transformação da realidade e a não reprodução das formas excludentes de conceber a educação. Nesse sentido, de acordo com as autoras, os cursos de Licenciatura em Educação do Campo têm compromisso não somente com a formação de professores, mas de educadores engajados na luta social e de construtores do futuro que, para tal, precisa se apoiar em processos formativos que incorporem as situações reais.

Assim, consideramos que, mesmo que a seleção do tema gerador não adote fielmente a metodologia em conformidade com o modelo de investigação temática, já indica o engajamento com a investigação sobre a realidade. Deste modo, inferimos que vai ao encontro da investigação sobre as relações homem-mundo, ou seja, investigar o pensar dos homens referido à realidade e seu atuar sobre a realidade que é sua práxis (FREIRE, 2019). Com isso, ratificamos que este compromisso se coaduna com os princípios de uma Educação do Campo engajada com a Alternância Integrativa ${ }^{6}$.

Portanto, apesar de faltarem elementos metodológicos na escolha do tema gerador, as intencionalidades relacionadas à investigação da relação dos sujeitos com a realidade, o pensar e o atuar crítico sobre ela se aproximam de uma educação dialógica e problematizadora de Paulo Freire (2019, p. 166) em que "os homens se sintam sujeitos de seu pensar, discutindo o seu pensar, sua própria visão de mundo, manifestada implícita ou explicitamente, nas suas sugestões e nas de seus companheiros".

\section{3) Seleção dos Instrumentos pedagógicos}

Os instrumentos pedagógicos na Alternância são recursos didáticos elaborados coletivamente pelos sujeitos envolvidos no processo formativo (professores, discentes, comunidade) que possibilitam o desenvolvimento de uma dinâmica de construção do

\footnotetext{
${ }^{6}$ Nesta pesquisa, recorremos à Alternância Verdadeira ou Integrativa como orientadora de um processo formativo pautado na práxis e que se distancia de modelos reducionistas de integração dos tempos e de espaços formativos. No processo formativo pautado na Alternância Verdadeira, teoria e prática compõem um todo indissoluvelmente ligado a uma vinculação efetiva dos meios de vida social, profissional e escolar, em uma unidade de tempo formativa (MALGLAIVE, 1975; SILVA, 2012). Não se trata, meramente, de uma sucessão de tempos teóricos e de tempos práticos organizados em um plano didático; mais que isso, representa um processo sustentado por uma estreita conexão. Nesta relação, os sujeitos envolvidos (escola e família) trabalham uma formação numa perspectiva de mão dupla, relacionando os conteúdos, complementando-os e enriquecendo-se reciprocamente.
} 
conhecimento, cujo ponto de partida é a realidade de vida dos estudantes do campo.

Sobreira e Silva (2014) destacam que estes instrumentos não nascem prontos; são gestados e aperfeiçoados frente às necessidades e aos desafios colocados na implementação de uma Alternância Verdadeira ou Integrativa. Desta forma, as diversas experiências educativas que utilizam a Alternância elegem e constroem instrumentos pedagógicos que atendam a realidade vivida por seus sujeitos e a compreensão que possuem sobre a relação entre os tempos e espaços formativos.

Na LEdoC/UFG-Regional Goiás, desde a primeira turma do curso, o Caderno de Realidade foi instituído como instrumento pedagógico da formação de professores de ciências. O Caderno de Realidade "abrange todas as atividades relacionadas diretamente ao tempo/espaço e dinâmica do Tempo Escola e TC, ajudando a valorização da relação do educando com a sua realidade" (BRASIL, 2020, p. 18).

Em reunião de planejamento, observamos que o Coordenador do Curso propõe:

Então o nosso exercício hoje aqui é primeiramente pensar o Caderno de Realidade. Qual é o objetivo dele? Qual vai ser o objetivo das atividades dentro desse Caderno de Realidade? (C; grifo nosso).

Assim, verificamos que, a partir do planejamento, os sujeitos envolvidos no processo formativo (professores e discentes) elaboram a proposta pedagógica e a organização deste instrumento. Ademais, o Caderno de Realidade sustenta o registro da Alternância no curso e é utilizado como instrumento de avaliação das disciplinas de Experiência Compartilhada.

$\mathrm{Na}$ construção do Caderno de Realidade, como primeira atividade, o discente é orientado a elaborar um Memorial em que deve expor a sua compreensão sobre si enquanto sujeito do campo, sua história, sua relação com o território e com a Educação do Campo. Essa atividade possibilita a reflexão sobre sua identidade camponesa e a importância de estar em uma formação de professores do campo.

Outro elemento presente neste caderno é o registro da pesquisa sobre a comunidade e das atividades desenvolvidas no TC, em reflexão e diálogo com as disciplinas desenvolvidas no TU, buscando a articulação dos tempos formativos.

No intuito de proporcionar a articulação entre os tempos e os espaços formativos, constatamos que o Caderno de Realidade apresenta o Tema Gerador do TC e questões construídas coletivamente de forma interdisciplinar pelos diferentes componentes curriculares da formação docente, com vistas à compreensão da realidade das comunidades em que estão inseridos os discentes da LEdoC. 
Eu acho que a gente poderia pensar o seguinte: ... pensar em atividades que percorram nossas quatro disciplinas e propor uma atividade única dentro desse caderno de realidade. $\mathrm{E}$ a gente propõe um ponto de reflexão de âmbito geral. (C; grifo nosso).

Nesse trecho, o coordenador refere-se às disciplinas que têm representação docente nesta reunião, de modo que estes se comprometem com a organização de uma atividade única e interdisciplinar que compõe parte do "Caderno de Realidade". Na proposta discutida, além de um espaço de registro das atividades e reflexões durante o TC, para futura avaliação da aprendizagem, engloba também a sistematização de um "Plano de Estudos".

O Plano de Estudos, por sua vez, dentro do Caderno de Realidade, propicia a articulação dos diferentes saberes (científicos, populares, culturais, entre outros) entre os tempos formativos. Neste instrumento, os diferentes componentes curriculares organizam as atividades e as reflexões que devem ser desenvolvidas no TC articuladas aos conteúdos dos diferentes componentes curriculares do TU.

Durante a coleta de dados desta pesquisa, no semestre de 2018-01, havia turmas de primeiro e terceiro períodos que cursavam a disciplina Experiência Compartilhada (I e III). Desse modo, as atividades do Caderno de Realidade estavam sendo pensadas para essas duas turmas. No entanto, a ausência de professores na atividade coletiva dificultou a construção interdisciplinar do Plano de Estudos.

Então a gente tá pensando nessas quatro disciplinas: matemática, biologia, filosofia e química do primeiro, né! Agora não podemos esquecer que a gente tem ainda o terceiro. [...] Pro terceiro período eu acho que a gente discute a física e a matemática como duas disciplinas proponentes pro Caderno de Realidade, a gente pode fazer assim esse diálogo. (C; grifo nosso).

Neste caso, acreditamos que a ausência de alguns professores formadores nas atividades de planejamento coletivo comprometeu o processo formativo de professores em Alternância. Além disso, inviabilizou a construção de um instrumento pedagógico interdisciplinar que represente um número significativo de componentes curriculares presentes na formação docente.

No semestre de 2018-2, o instrumento Caderno de Realidade continuou sendo utilizado, porém não houve reelaboração das orientações desse instrumento, o que pode ser observado pela ausência desta discussão nas pautas das reuniões do semestre. Nesse contexto, entendemos o Caderno de Realidade como instrumento articulador dos tempos e espaços formativos do curso, que contribui para a construção de uma Alternância Verdadeira e representa:

- A tomada de consciência e uma particular percepção da vida cotidiana do estudante; 
- O desenvolvimento da formação geral, porque retrata a história da família, da terra que trabalha, da comunidade e de outros aspectos que compõem a estrutura familiar;

- O compromisso com a transformação da realidade vivida pelo estudante, através do processo de tomada de consciência e análise sistematizada dessa realidade;

- Um elemento de orientação profissional, devido às reflexões registradas como resultado do trabalho do estudante, da vida profissional e social da família (BRASIL, 2020, p.18).

A partir da análise do desenvolvimento da Alternância e da importância que o Caderno de Realidade toma como instrumento pedagógico, compreendemos que ele representa no curso os elementos citados acima. No entanto, cabe destacar que não podemos perder de vista a necessidade de reflexões mais profundas neste instrumento sobre as narrativas da realidade das comunidades e as atividades desenvolvidas no TC. Ressaltamos ainda a importância da utilização deste instrumento nas disciplinas do TU02, principalmente por promover a articulação entre o TC e TU, tornando-se potencializador de uma Alternância Integrativa.

De outro modo, apesar dos instrumentos pedagógicos adotados (Caderno de Realidade, Memorial e Plano de Estudos) se aproximarem teoricamente de uma Alternância Integrativa, acreditamos que, devido à ausência do compromisso com o desenvolvimento coletivo do planejamento, a efetivação destes instrumentos contribuiu para o desenvolvimento de instrumentos pedagógicos inadequados, que não se articulam com a organização didática e pedagógica dos tempos e espaços formativos.

Desse modo, tal fato se opõe à proposta de Sobreira e Silva (2014) sobre a permanente construção dos instrumentos pedagógicos. Entendemos que é o trabalho coletivo contínuo no planejamento destes instrumentos que garante a avaliação e o aperfeiçoamento como atividades constantes para a construção do conhecimento em consonância com a realidade das comunidades de origem dos licenciandos da LEdoC.

Dito isto, consideramos que a compreensão que o curso demonstra sobre o processo formativo docente em Alternância não se efetiva na prática pedagógica pela ausência do compromisso com um trabalho coletivo, o que se torna obstaculizador de uma práxis educativa compromissada com a Educação do Campo e a luta do campesinato.

\section{CONSIDERAÇÕES FINAIS}

As atividades de planejamento e desenvolvimento da Alternância no curso de Licenciatura em Educação do Campo da UFG-Regional Goiás tem presente o compromisso dos sujeitos com um trabalho coletivo de maneira distinta. Ora este trabalho coletivo aparece como 
elemento facilitador da Alternância, ora a ausência dos formadores restringe o comprometimento com uma formação integrada entre os tempos e espaços educativos.

O planejamento transversalizou a maior parte das reuniões de colegiado, fazendo-se presente na construção dos dois tempos formativos (TU e TC), sendo considerado momento de reflexão, avaliação e tomada de decisões do processo educativo fundamental para a articulação dos tempos e processos formativos. Tal fato contribuiu diretamente para potencializar uma formação de professores em Alternância comprometida com a identidade do campesinato e com a articulação entre educação formal e os saberes da vida.

Contudo, a ausência do professor formador na construção de um instrumento pedagógico interdisciplinar compromete o processo formativo de professores em Alternância, indicando que urge romper com práticas e costumes de não envolvimento e não pertencimento a um processo formativo forjado nas lutas sociais, pois o movimento de Educação do Campo exige um compromisso com a coletividade e com a formação integral e humana do campesinato, o que não pode ser impulsionado sem a atitude de escuta do outro e do diálogo, de modo que a Alternância seja contínua, permanente e colaborativa.

\section{REFERENCIAS}

BARDIN, Laurence. Análise de conteúdo. 4 ed. Trad. Luís Antero Reto e Augusto Pinheiro. Lisboa, Portugal: Edições 70, 2010.

BITTENCOURT, Márcia; MOLINA, Mônica Castagna. Licenciatura em Educação do Campo da UnB: dos riscos às potencialidades na implementação. In: MOLINA, Mônica Castagna; HAGE, Salomão Mufarrej. Licenciaturas em Educação do Campo: resultados da pesquisa sobre os riscos e potencialidades de sua expansão. Florianópolis: LANTEC/CED/UFSC, 2019.

BRANDÃO, Carlos Rodrigues. Participar-pesquisar. In: BRANDÃO, Carlos Rodrigues. (Org.). Repensando a pesquisa participante. 3 ed. 3 reimp., São Paulo: Brasiliense, 1999.

BRASIL. MEC/CNE/CEB. Proposta de regulamentação da Pedagogia da Alternância. Brasília, 2020. Disponível em: http://portal.mec.gov.br/conselho-nacional-deeducacao/audiencias-e-consultas-publicas. Acesso em: 10 jun. 2020. Documento no prelo.

CALDART, Roseli Salete. Por uma Educação do Campo: traços de uma identidade em construção. In: ARROYO, Miguel Gonzalez; CALDART, Roseli Salete; MOLINA, Mônica Castagna (Orgs.). Por uma Educação do Campo. 5 ed., Petrópolis, RJ: Vozes, 2011.

CARDOSO, Elisandra Carneiro de Freitas. A formação de professores de Ciências na Licenciatura em Educação do Campo: tecendo tramas na Alternância. 2020, 229 f. Tese 
(Doutorado em Educação em Ciências e Matemática) - Programa de Pós-Graduação em Educação em Ciências e Matemática, Universidade Federal de Goiás, Goiânia, 2020.

CASTRO, Alessandra Gomes. Do rural ao campo: formação de professores para qual educação? 2020. 266f. Tese (Doutorado em Educação) - Programa de Pós-Graduação em Educação, Universidade Federal Fluminense, Rio de Janeiro, 2020.

FREIRE, Paulo. Pedagogia do Oprimido. 68 ed. Rio de Janeiro: Paz e Terra, 2019.

LIBÂNEO, José Carlos. Didática. São Paulo: Cortez, 1994.

MALGLAIVE, Gérard. La formartion alterneé des formateurs. Revue française de pédagogie. Paris, v. 30, p. 35-48, 1975.

MINAYO, Maria Cecília de Souza. Ciência, técnica e arte: o desafio da pesquisa social. In: MINAYO, Maria Cecília de Souza. (Org.). Pesquisa social: teoria, método e criatividade. $22^{a}$ ed., Petrópolis: Vozes, 1994.

MOLINA, Mônica Castagna; ANTUNES-ROCHA, Maria Isabel. Educação do Campo: história, práticas e desafios no âmbito das políticas de formação de educadores - reflexões sobre o PRONERA e o PROCAMPO. Revista Reflexão e Ação. Santa Cruz do Sul, v. 22, n. $02,2014$.

MOLINA, Mônica Castagna. Educação do Campo: novas práticas construindo Novos Territórios. In: ANTUNES-ROCHA, Maria Isabel; MARTINS, Maria de Fátima Almeida; MARTINS, Aracy Alves. Territórios educativos na Educação do Campo: escola, comunidade e movimentos sociais. 2 ed., Belo Horizonte: Gutenberg, 2012.

MOLINA, Mônica Castagna; ROCHA, Eliene Novaes; SANTOS, Clarice Aparecida. Riscos, potencialidades e desafios na consolidação da política de educação superior para os povos do campo na Universidade de Brasília (UnB). In: MOLINA, Mônica Castagna; HAGE, Salomão Mufarrej. Licenciaturas em Educação do Campo: resultados da pesquisa sobre os riscos e potencialidades de sua expansão. Florianópolis: LANTEC/CED/UFSC, 2019.

PUIG-CALVÓ, Pedro; GIMONET, Jean-Claude. Aprendizagens e relações humanas na Formação por Alternância. In: BEGNAMI, João Batista; BURGHGRAVE, Thierry (Orgs.). Pedagogia da Alternância e Sustentabilidade. Orizona: UNEFAB, 2013.

QUEIROZ, João Batista. Construção das Escolas Famílias Agrícolas no Brasil: Ensino Médio e Educação Profissional. 2004. 211f. Tese (Doutorado em Sociologia) - Programa de Pós-Graduação em Sociologia, Universidade de Brasília, Brasília, 2004.

SILVA, Antônio Fernando Gouvêa. A busca do tema gerador na práxis da Educação Popular. 21 ed., Curitiba: Gráfica Popular, 2007.

SILVA, Lourdes Helena. As experiências de formação de jovens do campo: alternância ou alternâncias? Curitiba: CRV, 2012.

. A pedagogia da alternância na educação do campo: velhas questões, novas perspectivas de estudo. Eccos Revista Científica. São Paulo, n. 36, p. 143-158, jan./abr. 2015. 
SOBREIRA, Milene Francisca Coelho; SILVA, Lourdes Helena. Vida e construção do conhecimento na Pedagogia da Alternância. Revista Eletrônica de Educação. São Carlos/SP, v. 08, n. 02, p. 212-227, 2014.

UFG. Universidade Federal de Goiás. Resolução CEPEC 1122. Regulamento Geral dos Cursos de Graduação. Goiânia, Gráfica UFG, 2012.

\section{SOBRE AS AUTORAS}

Elisandra Carneiro de Freitas é Doutora em Educação em Ciências e Matemática pela Universidade Federal de Goiás (UFG), Mestre em Educação em Ciências e Matemática, e graduada em Ciências Biológicas pela mesma instituição. Foi professora da Educação Básica e no Ensino Superior, no curso de Ciências Biológicas e na Faculdade de Educação. Atualmente é professora do curso de Licenciatura em Educação do Campo da Universidade Federal de Goiás (UFG). Tem experiência na área de Educação, com ênfase em formação de professores, atuando principalmente nos temas: educação popular, educação em ciências, educação do campo e educação ambiental. É vinculada à Rede de Pesquisadores sobre professores da Região Centro-Oeste (Redecentro) e ao grupo de pesquisa Educação no Cerrado e Cidadania.

E-mail: elisandra_carneiro@ufg.br

ORCID: https://orcid.org/0000-0001-9974-7013

Marilda Shuvartz é Doutora em Ciências Ambientais pela Universidade Federal de Goiás (UFG), Mestre em Educação Escolar Brasileira pela mesma instituição e graduada em Ciências Biológicas pela Pontifícia Universidade Católica do Rio Grande do Sul (PUC-RS). Docente aposentada do Instituto de Ciências Biológicas, onde também coordenou o Núcleo de Educação em Ciências e Meio AmbienteNECIMA. É professora do Programa de Pós-graduação em Educação em Ciências e Matemática da UFG, atuante na área de Educação em Ciências e Meio Ambiente. É membro da Associação Brasileira de Ensino de Biologia (SBEnBIO).

E-mail: marildas27@gmail.com

ORCID: https://orcid.org/0000-0002-2437-6622 